\title{
Research on the Influence for Stability of Surrounding Rock between Two-Step Method and CRD Method
}

\author{
Jun $\mathrm{Hu}$, Lingling Jin \\ Department of geotechnical, University of Science and Technology Liaoning, Anshan, 114051, China
}

\begin{abstract}
In the subway tunnel engineering, using different methods of tunnel excavation, the different influence on the stability of surrounding rock above class IV. Therefore, this paper is based on the specific engineering example. A subway tunnel in Dalian using FLAC3D software respectively adopts the CRD method and two-step method of excavation construction process in numerical simulation. By comparing the analysis of stress diagram and displacement after tunnel excavation and the range of plastic zone, researching these two methods impact on the stability of surrounding rock. Studying the results show this: The CRD method is adopted for surrounding rock in tunnel excavation above class IV. Not only decreasing the interference of the surrounding rock, but also controlling the total deformation and settlement of the surrounding rock. $T$ he stability of surrounding rock is improved.
\end{abstract}

Keywords-subway tunnel; two-step; CRD method; numerical simulation; IV level of surrounding rock.

\section{INTRODUCTION}

At present, the excavation of tunnel method has full face excavation method, partial excavation method, steps method .Partial excavation method used in poor condition of surrounding rock of the tunnel. Partial excavation method mainly includes CD method, CRD method and double side heading method and so on. Steps method in rock class requirements of demanding is less than full face excavation. Steps into long steps, short steps and micro step method. The partial excavation method and steps method are the more common method of excavation. The two excavation methods can decompose the settlement of surrounding rock deformation to each construction process in the process of tunnel excavation. As long as controlling the tunnel's displacement of every construction process, it can control the whole displacement of surrounding rock after the excavation of tunnel. Using FLAC3D software respectively adopts the CRD method and two-step method of excavation construction process in numerical simulation. Analyzing these two methods to impact the stability of surrounding rock.

\section{ENGINEERING SURVEY}

The metro engineering in Dalian has a lot of metro tunnels. The surrounding hills of tunnel are mainly moderately weathered slate. Moderately weathered slate is soft rock and the core is broken. So the quality rank of the rock is IV level. Tunnel area don't develop the surface water, ground water is mainly pore water and bedrock fissure water. In the engineering background of the subway tunnel, this project is divided into independent construction line. Advancing the left line and waiting for the excavation of 30 meter began to excavate the right line. For surrounding rock IV level, two- step and CRD method are put forward two kinds of construction schemes. Using the two-step method construction process as shown in figure 1 (a) as follows: Advanced small duct grouting reinforcement strata-the excavation in upper step - the application of earlier trimbering - the excavation in lower step - the application of earlier trimbering - the application of the secondary lining. When on the steps of construction excavation after $10 \mathrm{~m}$, When the excavation in upper step after 10 meters, then excavating in lower step . For the lower step excavation, the excavation each round to 1 meter when on the steps of construction excavation after 10 meter. The CRD method construction process as shown in figure 1 (b) as follows: advanced small duct grouting reinforcement strata-upper left pilot tunnel excavation - the application of earlier trimbering - the lower left side of the pilot tunnel excavation - the application of earlier trimbering - upper right pilot tunnel excavation-the application of earlier trimbering - the lower right side of pilot tunnel excavation - the application of earlier trimbering - the application of the secondary lining. The advanced small pipe support using phi $42 \mathrm{~mm}$ welded steel pipe, and steel pipe is made pointed cone and closed front end. Steel pipe every $15 \mathrm{~cm}$ crisscross cloth eyelet, and the eyelet is $10 \mathrm{~mm}$ in diameter. Pre mud glass double grout water injection is carried out on the rock reinforcement. System anchoring bolt length is 3.5 meters, and the welded steel pipe is Phi 42 . The application of earlier trimbering is supported by C20 concrete thickness of $20 \mathrm{~cm}$. The application of the secondary lining is used for C25 reinforced concrete thickness of $20 \mathrm{~cm}$ support.

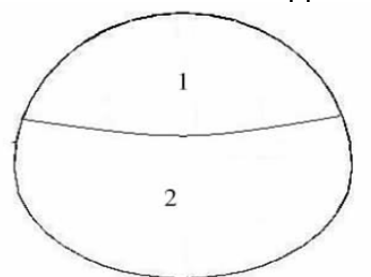

(a) Two-step Method

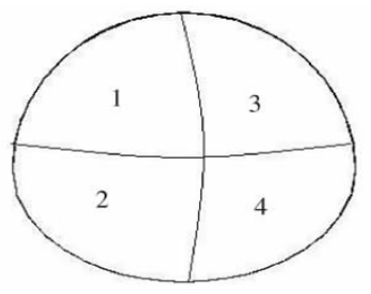

(b) CRD Method
Figure1. Construction Method

\section{NUMERICAL SIMULATION}

\section{A. Establish model}

On the basis of the typical sections of the left line of Dalian subway tunnel, establishing the three-dimensional 
model of the channel through the proper simplification. Coordinate system set in the cross-section of the tunnel for the $\mathrm{X}$ axis, $\mathrm{Y}$ axis is the axis of the tunnel direction, $\mathrm{Z}$ axis is the vertical direction of the tunnel. Along the cross section tunnel excavation, the width of excavation is 6.3 meters. The height of excavation is 6.51 meters. The threedimensional model is 50 meter along the $\mathrm{X}$ axis direction of positive and negative. In order to reduce the amount of calculation, the three-dimensional model is 1 meter along the $\mathrm{Y}$ axis direction. The model along the direction of $\mathrm{Z}$ axis is $25.55 \mathrm{~m}$, and negative direction is $34.55 \mathrm{~m}$. Because the model must be more than four times the size of the hole diameter of tunnel excavation, the model is about $100 \mathrm{~m} \times 60.1 \mathrm{~m} \times 1 \mathrm{~m}$. Boundary conditions: The left border $(\mathrm{X}$ $=-50 \mathrm{~m})$ and right border $(\mathrm{X}=50 \mathrm{~m})$ are horizontal displacement constraints. The model base $(Z=34.55 \mathrm{~m})$ is vertical displacement constraints. For the $\mathrm{Y}$ direction set $\mathrm{Y}$ direction of displacement constraints. The two-step method and CRD method are adopted to IV level surrounding rock excavation as shown in figure 2 and figure 3.

The numerical calculation obeys Mohr - Column yield criterion and using solid elements to simulate the surrounding rock. The null model is adopted to simulate the excavation surrounding rock. The beam elements are adopted to simulate the lead pipe. The anchor adopts the anchor cable unit simulation. The earlier trimbering adopts the shell element simulation. The secondary lining obeys elastic constitutive model and uses solid unit simulation.

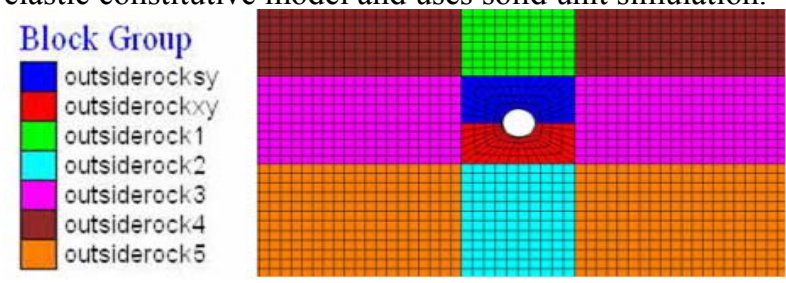

Figure 2. Two-step method excavation of tunnel model.

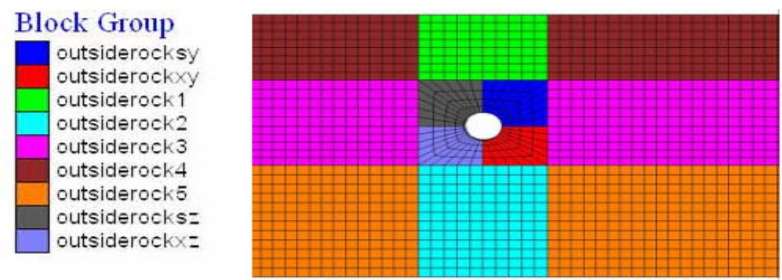

Figure 3. CRD method excavation of tunnel model.

\section{B. Parameter setting.}

Surrounding rock and supporting structure unit of material parameters are shown in table I, II.

TABLE I. SURROUNDING ROCK STRENGTH PARAMETERS.

\begin{tabular}{llllll}
\hline Name & $\begin{array}{l}\text { Gravity } \\
/ \\
\left(\mathrm{KN} / \mathrm{m}^{-}\right.\end{array}$ & $\begin{array}{l}\text { Cohesi } \\
\text { on/ } \\
\mathrm{Mpa}\end{array}$ & $\begin{array}{l}\text { Friction/ } \\
\left({ }^{\circ}\right)\end{array}$ & $\begin{array}{l}\text { tensi } \\
\text { on } \\
\mathrm{Mpa}\end{array}$ & $\begin{array}{l}\text { Poisson } \\
\text { Ration } / \mu\end{array}$ \\
\hline $\begin{array}{l}\text { Moderately } \\
\begin{array}{l}\text { Weathered } \\
\text { rock }\end{array}\end{array}$ & 22 & 0.5 & 27 & 0.2 & 0.3 \\
\hline
\end{tabular}

TABLE II. SUPPORTING STRUCTURE UNIT MATERIAL PARAMETERS.

\begin{tabular}{|c|c|c|c|c|}
\hline Name & $\begin{array}{c}\text { Gravit } \\
\mathrm{y} / \\
(\mathrm{KN} / \mathrm{m} \\
-3 \\
\end{array}$ & $\begin{array}{c}\text { Elasticity } \\
\text { Modulus/G } \\
\text { pa }\end{array}$ & $\begin{array}{c}\text { Poisso } \\
n \\
\text { Ration/ } \\
\mu\end{array}$ & $\begin{array}{l}\text { sectional } \\
\text { dimension }\end{array}$ \\
\hline anchor bolt & 38 & 120 & 0.3 & $\varphi 25 \mathrm{~mm}$ \\
\hline Pipe roof & 35 & 114 & 0.3 & $\varphi 105 \mathrm{~mm}$ \\
\hline $\begin{array}{l}\text { Earlier } \\
\text { trimbering }\end{array}$ & 25 & 21 & 0.2 & $\begin{array}{c}\text { thickness } 20 \mathrm{c} \\
\mathrm{m}\end{array}$ \\
\hline $\begin{array}{l}\text { secondary } \\
\text { lining }\end{array}$ & 26 & 25 & 0.2 & $\begin{array}{c}\text { thickness } 40 \mathrm{c} \\
\mathrm{m}\end{array}$ \\
\hline
\end{tabular}

\section{NUMERICAL ANALYSIS}

Using FLAC3D to simulate two-step and CRD method respectively in the process of tunnel excavation. Comparating analysis of surrounding rock stress diagram and displacement and plastic damage and studying the two methods in the impact on the surrounding rock stability in tunnel excavation.

\section{A. Stress analysis of surrounding rock}

The tunnel after excavation of the principal stress nephogram of the surrounding rock as shown in figure 4 and figure 5.It can be seen from the principal stress nephogram that the two excavation methods appear stress concentration phenomenon in the arch foot. Through the comparison on the graph, it can be found the surrounding rock around tunnel contour principal stress value is bigger. The maximum principal stress in the arch foot, which is about $0.1 \mathrm{Mpa}$. The minimum principal stress of surrounding rock is about $0.3 \mathrm{Mpa}$. However , using two-step of principal stress value after the excavation of tunnel surrounding rock is relatively small. The maximum principal stress in the arch foot, which is about $0.05 \mathrm{Mpa}$,. The minimum principal stress of surrounding rock is about $0.2 \mathrm{Mpa}$. Thus it can be seen the maximum principal stress of CRD method is twostep excavation 2 times. T he minimum principal stress of surrounding rock is 1.5 times two-step excavation.

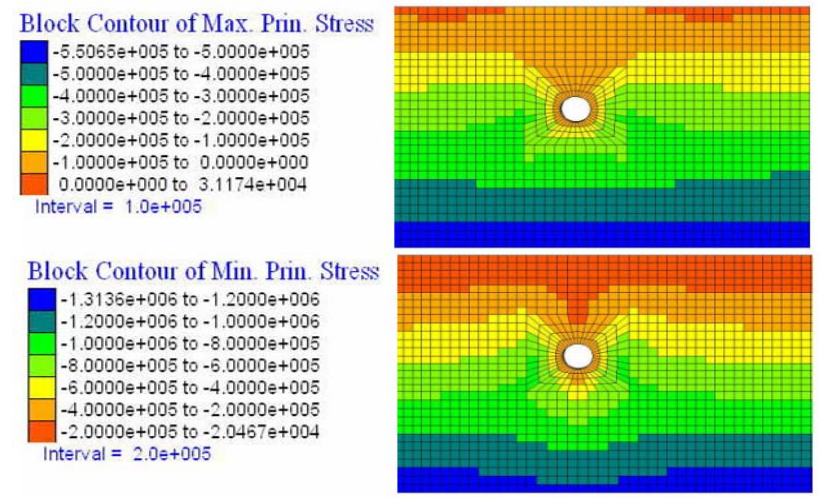

Figure 4. CRD method of principal stress distributing graph.

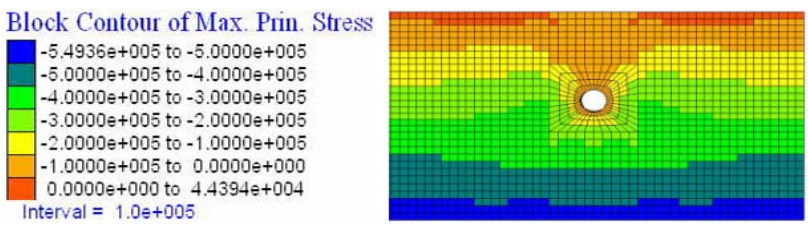


Block Contour of Min. Prin. Stress

$-1.3154 e+006$ to $-1.2000 e+006$ $-1.2000 e+006$ to $-1.0000 e+006$ $-1.0000 e+006$ to $-8.00000+005$ $-8.0000 e+005$ to $-6.0000 e+005$ $-6.0000=+005$ to $-4.0000=+005$ $-4.0000 e+005$ to $-2.0000=+005$

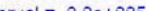

Figure 5. Two-step method of principal stress distributing graph

\section{B. Displacement deformation analysis of surrounding rock.}

The excavation of tunnel displacement nephogram as shown in figure 6 and figure 7. Through the vertical displacement contours can be seen after excavation. The vertical displacement of the tunnel after CRD method excavation and arch sedimentation value are less than twostep method after excavation. The CRD method tunnel in vaults maximum magnitude is about $10.988 \mathrm{~mm}$. However, using two- step method in tunnel vault settlement value is about $18.05 \mathrm{~mm}$. When the two-step method is adopted after the excavation of tunnel, the main settlement deformation appeared in the vault above and the deformation of the range is larger. Because upper step on the excavation area is larger and the stress equilibrium constraints. All the damage from three to stress state for two to the stress state. For IV level relatively weaker surrounding rock, constraints are prone to shear failure. So as to move within a larger space and increase the settlement of the vault. At the same time, because the lining can't be closed in time, thus prolonged exposure outside of surrounding rock. Eventually causing settlement of surrounding rock is larger. The CRD method is adopted after the excavation of tunnel. The mainly settlement deformation appears to the right place in the vault and the range of deformation is smaller. When the left side of the tunnel excavation construction by adopting the CRD method, its lining support rapidly construct. Thus limiting the part of the settlement of surrounding rock deformation. Due to the constraints of the surrounding rock is not enough in the right side of the excavation, the settlement and deformation value of the displacement is relatively more. when the right hand side after excavation, the cumulative displacement value is more than the left. CRD method for excavation construction process has influence on the settlement of displacement of surrounding rock deformation. We should try to avoid adverse settlement in construction to ensure the stability of surrounding rock.

It can be seen by comparing the horizontal displacement nephogram that the horizontal displacement of the tunnel is relatively small by adopting the CRD method after the excavation of tunnel. Its maximum value at the right side of the arch foot is about $8.156 \mathrm{~mm}$. However, adopting the two-step method after the excavation of tunnel, the maximum horizontal displacement occurs in the arch foot is about $13.136 \mathrm{~mm}$. Thus adopting CRD method can better control the displacement of tunnel surrounding.

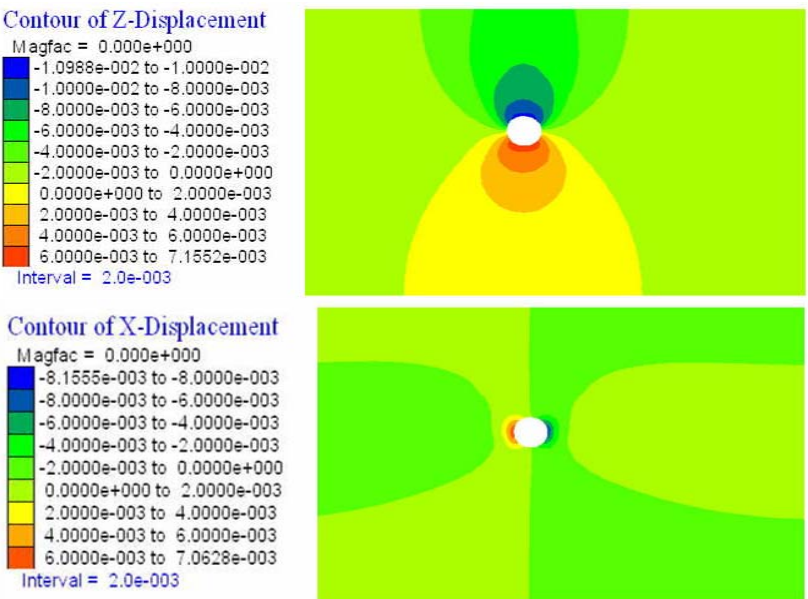

Figure 6. CRD method after excavation displacement nephogram.

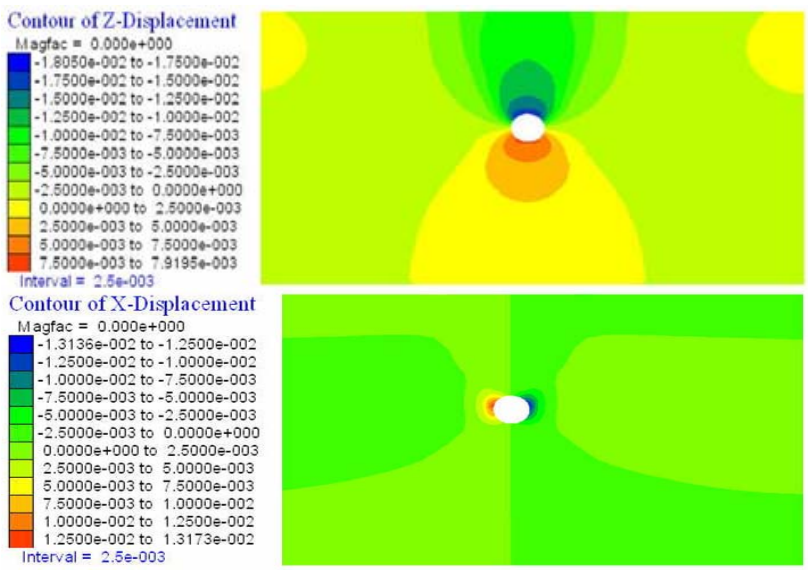

Figure 7. Two-step method after excavation displacement nephogram

\section{Analyze plastic damage area.}

The excavation of tunnel plastic zone as shown in figure 8 and figure 9. It can be seen that the CRD method is adopted after the excavation of the plastic zone of surrounding rock area are mainly concentrated in the four corners of the tunnel. However, after the excavation of tunnel by adopting the up and down the steps method, the lower range of surrounding rock mass with the method of CRD excavation is roughly the same. But the upper arch is deeper. Because it has larger disturbance on the surrounding rock after upper steps on the excavation and there is no timely closed loop, leading to the upper arch settlement deformation of surrounding rock.
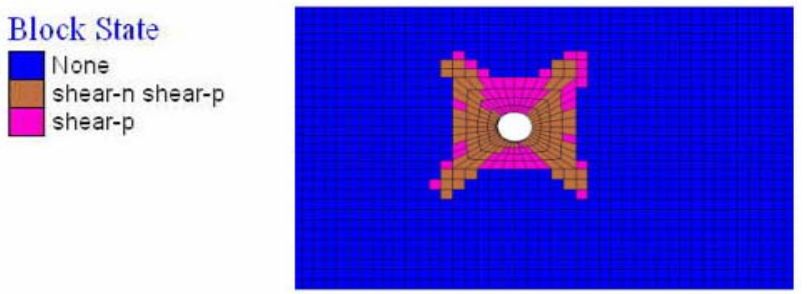

Figure 8. CRD method of excavation to produce the plastic zone. 


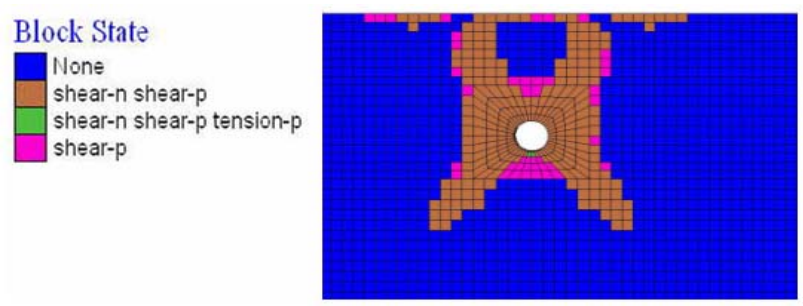

Figure 9. Two-step method of excavation to produce the plastic zone.

\section{CONCLUSIONS}

By using simulation of FLAC3D and combining with previous engineering experience can get the following conclusions. (1)According to the stress nephogram, the maximum principal stress and minimum principal stress values by using two- step method of excavation are slightly larger than adopting the CRD excavation of numerical method. (2) According to the displacement diagram, the displacement of the end of the tunnel vault and arch excavation of numerical values by using two-step method of excavation are greater than the CRD method and horizontal displacement are also greater than CRD method of numerical value. (3) According to the plasticity chart, the two methods to produce the failure form of plastic zone and the lower range of surrounding rock are the same. However, the upper arch plastic zone developed deeper by using twostep method. In conclusion, the CRD method which is adopted in the process of tunnel excavation has little effect on the stability of surrounding rock. It can control the overall settlement deformation of surrounding rock and improve the stability of the tunnel in the process of excavation of the tunnel surrounding rock.

\section{REFERENCES}

[1] Cui Xiaopeng, Sun Shaofeng. Comparison and contrast between CRD excavation method and 3-bench 7-step excavation method and their optimization. In: Tunnel Construction, Edition2010, Number2.

[2] Wei Bingxu,Tang Huixiang. Crd method and Two-step method in tunnel excavation effect of contrast and numerical analysis. In: The Chinese and foreign road,Edition2011,Number31.

[3] Teng Haiwen. Shenyang subway tunnel excavation based on FLAC3D three-dimensional stability analysis. In:Journal of Beijing University of Technology,Edition2009,Number35.

[4] Guo Yanjing, Huang Mingqi. Comparison and contrast between CRD excavation method and double wall method through sand layer in Xiamen xiang'an undersea tunnel. In:China railway science,Edition2009, Number30. 